\title{
Uveíte na artrite idiopática juvenil: Fatores clínicos e Laboratoriais
}

\section{Lúcia Helena X. Baltazar*, Débora P. Souza, Marcelo Paccola, Roberto Marini, Simone Appenzller}

\section{Resumo}

A uveíte é caracterizada por uma inflamação do trato uveal, sendo essa a manifestação extra-articular mais comum na artrite idiopática infantil (AIJ). Essa manifestação é mais prevalente em crianças do sexo feminino com fator antinuclear (FAN) positivo e pode evoluir para complicações sérias e irreversíveis como catarata, ceratopatia em faixa, degeneração de mácula e até cegueira. O estudo visa avaliar a frequência e os fatores clínicos e laboratoriais associados a essa manifestação nos pacientes em seguimento no HC-UNICAMP, a fim da melhor organização de interconsultas da oftalmologia.

Palavras-chave:

Uveíte, AIJ, Manifestações extra-articulares

\section{Introdução}

A AlJ é caracterizada pela presença de artrite crônica com início antes dos 16 anos e duração de pelo ao menos seis semanas. Apresentando tanto manifestações articulares como extra-articulares. $(1,2,3)$

Dentre as manifestações extra-articulares as mais comuns são uveíte, psoríase e dactilite. Sendo a uveíte a mais prevalente dessas. (3)

A uveíte caracteriza-se pela inflamação do trato uveal, sendo classificada em anterior, intermediária, posterior e pan uveíte, de acordo com o local de acometimento. Pode ser classificada também em aguda e crônica, segundo o tempo de atividade. $(3,4)$

Os sintomas clínicos são dor, fotofobia, lacrimejamento, cefaleia, hiperemia conjuntival e diminuição da acuidade visual. Entretanto, muitos pacientes são assintomáticos e podem evoluir diretamente para complicações graves e irreversíveis como catarata, ceratopatia em faixa e até cegueira. (4)

Assim, faz-se necessário o estudo dessa manifestação pela alta morbidade, sendo importante avaliação dos fatores associados a ocorrência. Além disso, o estudo visa a melhor organização do serviço quanto ao número de pacientes a serem avaliados pelo oftalmologista e a determinar os fatores clínicos e laboratoriais prevalentes.

\section{Resultados e Discussão}

$\mathrm{Na}$ análise dos dados obtidos dos prontuários dos 239 pacientes, foi constatado que $26(10,9 \%)$ pacientes com AlJ em seguimento no ambulatório de reumatologia do HC-UNICAMP apresentam uveíte, sendo a manifestação extra articular mais prevalente. Esse dado apresentado está de acordo com a literatura que varia grandemente entre $8 \%$ a $67 \%$. $(2,4)$

Foi constatado, assim como na literatura, que há uma maior prevalência desses casos em mulheres $(53,8 \%)$, AlJ oligoarticular $(46,1 \%)$ e fator antinuclear (FAN) positivo $(57,7 \%)$. $(1,2,3,4)$

A partir dos dados é possível observar que a média de diagnóstico de idade de AIJ é de aproximadamente 6 anos tanto em pacientes com uveíte quanto sem. E ainda a média de idade de diagnóstico de uveíte nesses pacientes é de 10,9. Diferente da literatura consultada que apresenta uma média de idade inferior. (5)

Em relação aos episódios de uveíte, têm-se uma prevalência de uveíte anterior $(69,5 \%)$, de curso agudo $(52,5 \%)$, com acometimento unilateral $(54,2 \%)$, de duração menor que 3 meses $(50,8 \%)$ e com ausência de atividade articular durante os episódios $(50,8 \%)$. Sendo observado uma discordância com os estudos internacionais que apresentam uveíte anterior crônica mais prevalente do que a aguda $(1,2,3,4)$, além disso, há maior prevalência de uveíte bilateral. (3)

Outro dado importante constatado é a maior prevalência de catarata $(19,2 \%)$ como complicação ocular, seguido por glaucoma $(11,5 \%)$. Também concordante com autores de outros estudos. $(2,3,4,5)$

Gráfico 2. Dados uveíte

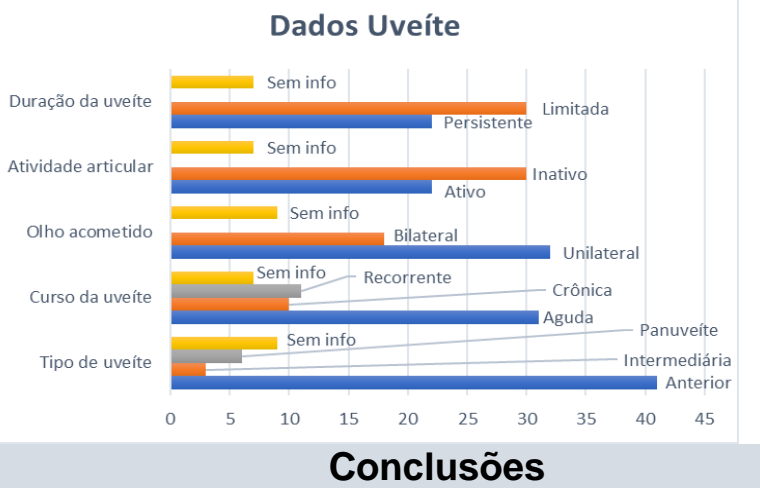

Conclui-se que no HC-UNICAMP, há uma maior prevalência de uveíte na AlJ em pacientes do sexo feminino, oligoarticular, FAN positivo. Dessa forma, fazse necessário um acompanhamento maior na oftalmologia desse grupo de pacientes, sendo recomendado em literatura a cada 3 meses.

Percebe-se também que 0 diagnóstico da uveíte acontece em média 4 anos depois do diagnóstico da AlJ, um padrão maior que o internacional. Sendo importante, uma investigação periódica mesmo em pacientes assintomáticos para uveíte, já que é visto um número maior de diagnósticos assintomáticos em outros estudos.

\section{Agradecimentos}

Ao CNPQ e Pró-reitoria de pesquisa UNICAMP pela concessão da bolsa PIBIC que possibilitou a realização dessa iniciação científica.

${ }^{1}$ BARUT, K. et al. Juvenile Idiopathic Arthritis. Balkan Med Journal. v. 34, n.2, p. $90-101$, mar. 2017.

${ }^{2}$ HAWKINS, M. J. et al. Managing juvenile idiopathic arthritis-associated uveitis. Survey of Ophthalmology. V. 61, i. 2, p. 197-210, 2016.

3 SAURENMANN, R. K. et al. Prevalence, Risk Factor, and Outcome of Uveitis in Juvenile Idiopathic Arthritis. Arthritis \& Rheumatism. V. 56, n. 2, p. 647-657, feb. 2007

${ }^{4}$ CLARKE S. L. N.; SEN, E. S.; RAMANAN, A. V. Juvenile idiopathic arthritisassociated uveitis. Pediatric Reumatology. v. 14, n. 1, p.1, 2016.

5 VELA, J. I. et al. Uveítis anterior y artritis idiopática juvenil. Arch Soc Esp Oftalmol. v. 78 , n. 10 , p. 561-565, oct. 2003 